\title{
Determination of MLN0128, An Investigational Antineoplastic Agent, in Human Plasma by LC-MS/MS
}

\author{
Sandeep R. Kunati \\ Cleveland State University \\ Yan Xu \\ Cleveland State University, y.xu@csuohio.edu
}

Follow this and additional works at: https://engagedscholarship.csuohio.edu/scichem_facpub

Part of the Analytical Chemistry Commons

How does access to this work benefit you? Let us know!

\section{Publisher's Statement}

This is the accepted version of the following article: Kunati, S. R.; Xu, Y. Determination of MLN0128, an investigational antineoplastic agent, in human plasma by LC-MS/MS. Biomedical Chromatography 2017,31 , e3818-n/a., which has been published in final form at http://onlinelibrary.wiley.com/doi/10.1002/bmc.3818/full

\section{Recommended Citation}

Kunati, Sandeep R. and Xu, Yan, "Determination of MLN0128, An Investigational Antineoplastic Agent, in Human Plasma by LC-MS/MS" (2016). Chemistry Faculty Publications. 179.

https://engagedscholarship.csuohio.edu/scichem_facpub/179

This Article is brought to you for free and open access by the Chemistry Department at EngagedScholarship@CSU. It has been accepted for inclusion in Chemistry Faculty Publications by an authorized administrator of EngagedScholarship@CSU. For more information, please contact library.es@csuohio.edu. 


\title{
Determination of MLN0128, an investigational antineoplastic agent, in human plasma by LC-MS/MS
}

\author{
Sandeep R. Kunat Yan Xu
}

\begin{abstract}
MLN0128, an mTOR kinase inhibitor, is currently undergoing clinical investigation for treatment of a variety of cancers. To support this work, an LC-MS/MS method has been developed for the determination of MLN0128 in human plasma. A structural analog STK040263 was used as the internal standard. Both MLN0128 and the IS were first extracted from plasma using methyl tert-butyl ether; then separated on a Waters $X T$ Terra ${ }^{\circledR} M S C_{18}$ column using a mobile phase consisting of methanol-acetonitrile-10.0 mM ammonium formate $(34: 6: 60, \mathrm{v} / \mathrm{v} / \mathrm{v})$ at a flow rate of $0.300 \mathrm{~mL} \min ^{1}$. Quantitation of MLN0128 was done by positive electrospray ionization tandem mass spectrometry in multiple-reaction-monitoring mode. This method has a total run time of $<4 \mathrm{~min}$ with the retention times of 1.95 and $2.94 \mathrm{~min}$ for the IS and MLN0128, respectively. The method has been validated per the US Food and Drug Administration guidance for bioanalytical method validation. It has a calibration range of $0.100-50.0 \mathrm{ng} \mathrm{mL}^{1}$ in human plasma with a correlation coefficient $>0.999$. The overall assay accuracy and precision were $\leq \pm 4$ and $\leq 8 \%$, respectively. The IS normalized recovery of MLN0128 was $98-100 \%$. The stability studies showed that MLN0128 was stable under all tested conditions. The method developed may be useful for clinical studies of MLN0128.
\end{abstract}

\section{KEYWORDS}

human plasma, LC-MS/MS, method validation, MLN0128, TORC1/2 inhibitor

\section{INTRODUCTION}

MLN0128 (also known as INK128) is a potent, small-molecule anticancer agent developed by Millennium Pharmaceuticals. MLN0128 is an orally active and highly selective inhibitor of mTOR (mammalian target of rapamycin) kinase which has two distinct multi-protein complexes, TORC1 and TORC2 (TORC1/2), for regulating critical aspects of cell survival, proliferation and metastasis (Guertin \& Sabatini, 2007; Meric-Bernstam \& Gonzalez-Angulo, 2009). TORC1/2 are upregulated in some tumors and play important roles in the $\mathrm{PI} 3 \mathrm{~K} / \mathrm{Akt} / \mathrm{mTOR}$ signaling pathway, which is often dysregulated in human tumorigenesis (Shaw et al., 2004; Neshat et al., 2001; Inoki, Zhu, \& Guan, 2003; Vivanco \& Sawyers, 2002). The mechanism of MLN0128 for treatment of cancer is that the agent competes with ATP for binding to and inhibiting TORC1/2 active sites,

Abbreviations used: ESI, electrospray ionization; LLE, liquid liquid extraction; $M F$, matrix factor; MRM, multiple reaction monitoring; MTBE, methyl tert butyl ether. which may result in tumor cell death and halt tumor cell growth (Schenone, Brullo, Musumeci, Radi, \& Botta, 2011).

MLN0128 has shown activity against a large number of human tumor cell lines with diverse tissue origins and genetic makeups including acute lymphoblastic leukemia, renal cell carcinoma, prostate, breast, endometrial and lung cancers and demonstrated inhibitory activity toward mTOR signaling in human tumor xenograft mouse models with well-defined pharmacological properties (Janes et al., 2013; Liu et al., 2010; Ingels et al., 2014; Gökman-Polar et al., 2012; Edlind \& Hsieh, 2014; Fabrey, Atienza, Briere, Brake, \& Vincent, 2013). To date, two Phase I clinical trials of MLN0128 have been conducted, which showed acceptable safety profiles (Infante et al., 2013; Burris et al., 2012). These findings warrant further clinical trials of MLN0128 in patients with various advanced and recurrent cancers (https://www.clinicaltrials.gov/ct2/results? term $=$ MLN0128\&Search $=$ Search, accessed 7 August 2016)

Since there is no published analytical method available for pharmacological study of MLN0128 in human based on the recent Scifinder $($ database search and the need of such method for clinical 
studies is present and real, we have developed a liquid chromatography tandem mass spectrometry method in this work for quantitative determination of MLN0128 in human plasma to support the clinical development of the drug. The method developed has been validated according to the US Food and Drug Administration (US-FDA, 2001) guidance for industry on bioanalytical method validation with the intention to be used for pharmacokinetic study of MLN0128 in clinical trials.

\section{EXPERIMENTAL}

\section{Chemicals}

MLN0128 \{3-(2-aminobenzo[d]oxazol-5-yl)-1-isopropyl-1H-pyrazolo [3,4-d] pyrimidin-4-amine, $\mathrm{C}_{15} \mathrm{H}_{15} \mathrm{~N}_{7} \mathrm{O}$ \} was purchased from Selleckchem (Houston, TX, USA) (catalog no. S2811, purity >99.64\%). STK040263 \{1-benzyl-1H-pyrazolo [3,4-d]pyrimidin-4-amine, $\mathrm{C}_{12} \mathrm{H}_{11} \mathrm{~N}_{5}$ \} (as internal standard, IS, purity $>90 \%$ ) was purchased from Vitas-M Laboratory (Apeldoorn, Netherlands). LC/MS-grade methanol $(\mathrm{MeOH}), \mathrm{LC} / \mathrm{MS}$-grade acetonitrile, HPLC-grade water, HPLC-grade methyl tert-butyl ether (MTBE) and ACS-grade dimethylsulfoxide were purchased from Fisher Scientific (Pittsburgh, PA, USA). Ammonium formate was from Sigma-Aldrich (St Louis, MO, USA). Blank pooled human plasma and six individual lots of blank human plasma with specific lot numbers (IR11-1670, 1M2070-01, 1M2070-02, $1 \mathrm{M} 2070-03,1 \mathrm{M} 2070-04,1 \mathrm{M} 2070-05$ and $1 \mathrm{M} 2070-06)$ were purchased from Innovative Research (Novi, MI, USA).

\section{Instrumentation}

The liquid chromatography tandem mass spectrometry (LC-MS/MS) system used in this work consisted of a Shimadzu (Columbia, MD, USA) Prominence UFLC unit with a controller (CBM-20 A), two binary pumps (LC-20 AD) and an autosampler (SIL- 20 AC), and an AB Sciex (Foster City, CA, USA) API3200 turbo-ion-spray ${ }^{\circledR}$ triple quadruple tandem mass spectrometer equipped with an electrospray ionization (ESI) probe and a syringe pump. The LC-MS/MS system was controlled by $A B$ Sciex Analyst ${ }^{\circledR}$ (version 1.5.1) software for its operation, data acquisition and processing.

\section{Liquid chromatography}

Chromatographic separation of MLN0128 and the IS was carried out isocratically at room temperature on a Waters (Milford, MA, USA) $X$ Terra ${ }^{\circledR} M \mathrm{MS} \mathrm{C}_{18}$ column $(2.1 \times 50 \mathrm{~mm}, 3.5 \mu \mathrm{m})$ connected to a Waters XTerra ${ }^{\circledR} M S C_{18}$ guard column $(2.1 \times 10 \mathrm{~mm}, 3.5 \mu \mathrm{m})$ with mobile phase consisting of methanol-acetonitrile-ammonium formate $(10.0 \mathrm{mM}, \mathrm{pH} 2.8 ; 34: 6: 60, \mathrm{v} / \mathrm{v} / \mathrm{v})$ pumped at a flow rate of $0.300 \mathrm{~mL}$ min ${ }^{1}$. Acetonitrile was used as the wash solvent between injections. For each analysis, $10.0 \mu \mathrm{L}$ of sample was injected into the system by autosampler set at $4^{\circ} \mathrm{C}$, and the total run time was 4 min.

\section{Tandem mass spectrometry}

Mass spectrometric detection was carried out using positive electrospray ionization $\left(\mathrm{ESI}^{+}\right)$mode, which was tuned for compounddependent and source-dependent parameters by separate infusion of MLN0128 (500 ng mL ${ }^{1}$ ) and IS (500 ng mL ${ }^{1}$ ) in the mobile phase by the syringe pump at a flow rate of $10 \mu \mathrm{L}$ min ${ }^{1}$. The optimized parameters were as follows: curtain gas at $45 \mathrm{psi}$; collision gas at $3 \mathrm{psi}$; ion spray voltage at $5500 \mathrm{~V}$; temperature at $600^{\circ} \mathrm{C}$; ion source gas 1 at $55 \mathrm{psi}$; ion source gas 2 at $45 \mathrm{psi}$; declustering potential at $60 \mathrm{~V}$; entrance potential at $7.5 \mathrm{~V}$; collision energy at $35 \mathrm{eV}$; collision cell exit potential at $4 \mathrm{~V}$; and resolution at 0.7 units. Quantitation of MLN0128 and IS was done in multiple-reaction-monitoring (MRM) mode with the mass transitions, $m / z 310 \rightarrow 268$ for MLN0128, and $m / z 226 \rightarrow 127$ for the IS, respectively, using a dwell time of $400 \mathrm{~ms}$ for each analyte.

\section{Preparation of stock and working solutions}

The stock solutions of MLN0128 (1.00 mg mL ${ }^{1}$ ) and IS (1.00 mg mL ${ }^{1}$ ) were prepared as follows: MLN0128 and the IS (1 mg or more) were weighed out precisely on a Mettler Toledo (Greifensee, Switzerland) XS20 model analytical balance to $0.01 \mathrm{mg}$, and each standard compound dissolved in an appropriate volume of dimethylsulfoxide to make a concentration of $1.00 \mathrm{mg} \mathrm{mL}{ }^{1}$. These stock solutions were kept in a freezer at $-20^{\circ} \mathrm{C}$ before use. The working solutions of MLN0128 $\left(1.00 \mu \mathrm{gL}^{1}\right)$ and the IS $\left(1.00 \mu \mathrm{gL}^{1}\right)$ were freshly prepared by serial dilution of each stock solution with the mobile phase.

The stock solution of ammonium formate $(0.100 \mathrm{M})$ was prepared by dissolving appropriate amount of ammonium formate salt in a known volume of HPLC-grade water and stored in a refrigerator at $4^{\circ} \mathrm{C}$ before use. The working solution of ammonium formate $(10.0 \mathrm{~mm})$ was prepared by a 10 -fold dilution of the stock solution with HPLC-grade water and adjusted to $\mathrm{pH} 2.8$ using formic acid, if necessary.

\section{Preparation of standard solutions}

The standard solutions of MLN0128 (1.00, 2.00, 2.50, 5.00, 10.0, 25.0, $30.0,50.0,100,200,250,300,400$ and $500 \mathrm{ng} \mathrm{mL}^{1}$ ) were prepared daily by sequential dilution of the working solution with the mobile phase to make higher concentrations of the standard solutions (e.g. 100, 200, 250, 300, 400 and $500 \mathrm{ng} \mathrm{mL}^{1}$ ) and by serial dilutions of these standard solutions with the mobile phase to make lower concentrations of the standard solutions (e.g. 1.00, 2.00, 2.50, 5.00, 10.0, 25.0, 30.0 and $50.0 \mathrm{ng} \mathrm{mL}^{1}$ ). The standard solution of the IS at concentration of $50 \mathrm{ng} \mathrm{mL}^{1}$ was prepared freshly by direct dilution of working solution of the IS with the mobile phase.

\section{Preparation of plasma calibrators and quality controls}

Plasma MLN0128 calibrators $(0.100,0.200,0.500,1.00,2.50,5.00$, 10.0, 25.0 and $50.0 \mathrm{ng} \mathrm{mL}^{1}$ ) were prepared by mixing $10.0 \mu \mathrm{L}$ of each MLN0128 standard solution (1.00, 2.00, 5.00, 10.0, 25.0, 50.0, 100, 250 and $500 \mathrm{ng} \mathrm{mL}^{1}$ ) with $90.0 \mu \mathrm{L}$ of blank pooled human plasma. The zero calibrator (or single blank plasma) was prepared by mixing $10.0 \mu \mathrm{L}$ of the mobile phase with $90.0 \mu \mathrm{L}$ of blank pooled human plasma. Plasma MLN0128 quality controls (QCs) $(0.25,3.00$ and $40.0 \mathrm{ng} \mathrm{mL}{ }^{1}$ ) were prepared by mixing $10.0 \mu \mathrm{L}$ of each MLN0128 standard solution (2.50, 30.0 and $400 \mathrm{ng} \mathrm{mL}{ }^{1}$ ) with $90.0 \mu \mathrm{L}$ of blank pooled human plasma. The plasma MLN0128 calibrators and QCs were stored at $-20^{\circ} \mathrm{C}$ before use. 


\section{Plasma sample preparation}

Plasma samples (e.g. calibrator and QC) were thawed to room temperature and placed in disposable borosilicate glass tubes $(13 \times 100 \mathrm{~mm})$ from VWR (Radnor, PA, USA). For each $100 \mu \mathrm{L}$ of plasma sample, $10.0 \mu \mathrm{L}$ of the IS $\left(50.0 \mathrm{ng} \mathrm{mL}{ }^{1}\right)$ were added except the double blank plasma where $10.0 \mu \mathrm{L}$ of the mobile phase were added. After vortexing for $30 \mathrm{~s}, 2 \mathrm{~mL}$ of MTBE were added to the sample tube, and the liquid phases were mixed in a multi-tube vortex mixer (Troemner, Thorofare, NJ, USA) for $5 \mathrm{~min}$ to extract the analytes, then centrifuged in a Sorvall ST4OR centrifuge (Thermo Scientific, Waltham, MA, USA) at $4816 \times \mathrm{g}$ at $4^{\circ} \mathrm{C}$ for $8 \mathrm{~min}$. The organic phase (upper layer) was transferred into a fresh borosilicate glass tube and dried in a TurboVap ${ }^{\circledR}$ LV evaporator (Caliper Life Sciences, Hopkinton, MA, USA) at $30^{\circ} \mathrm{C}$ under nitrogen gas at a pressure of $20 \mathrm{psi}$ for $12 \mathrm{~min}$. The resultant dried residue was reconstituted in $100 \mu \mathrm{L}$ of a reconstitution solution containing methanol and $10 \mathrm{mM}$ ammonium formate $(\mathrm{pH} 2.8)(1: 9, \mathrm{v} / \mathrm{v})$ for the subsequent LC-MS/MS analysis.

\section{Method validation}

The method developed was validated in human plasma following the US Food and Drug Administration guidance for industry on bioanalytical method validation in terms of selectivity, lower limit of quantitation, matrix effect, recovery, linear calibration range, accuracy and precision, as well as stabilities for short-term sample processing and long-term sample storage.

\section{Selectivity and lower limit of quantitation}

The selectivity of this method was assessed by any interferents observed at the retention times and mass transitions of MLN0128 and the IS in six individual blank human plasma and blank pooled human plasma matrices. The lower limit of quantitation (LLOQ) of the method was defined as the lowest concentration of MLN0128 plasma calibrator with accuracy expressed as percent relative error (RE) and precision expressed as percentage coefficient of variation (CV) at $\leq \pm 20$ and $\leq 20 \%$, which was validated in six individual and pooled human plasma matrices.

\section{Matrix factor and recovery}

The absolute matrix factor (MF) of MLN0128 (or the IS) was determined by the mean peak area of MLN0128 (or the IS) at a specified concentration in the extracted plasma matrix over that of MLN0128 (or the IS) at the concentration in the reconstitution solution. The IS normalized MF was determined by the absolute MF of MLN0128 over that of the IS. For this study, MLN0128 QCs at three concentrations $\left(0.250,3.00\right.$ and $\left.40.0 \mathrm{ng} \mathrm{mL}^{1}\right)$ with a fixed concentration of the IS (5.00 ng mL ${ }^{1}$ ) were prepared in six individual extracted plasma matrices and in the reconstitution solution.

The absolute recovery of MLN0128 (or the IS) was determined by the mean peak area of MLN0128 (or the IS) at a specific concentration in plasma matrix over that of MLN0128 (or the IS) at the concentration in the extracted plasma matrix multiplying by $100 \%$. The IS normalized recovery was determined by the absolute recovery of MLN0128 over that of the IS multiplying by $100 \%$. For this study, MLN0128 QCs at three concentrations $\left(0.250,3.00\right.$ and $\left.40.0 \mathrm{ng} \mathrm{mL}{ }^{1}\right)$ with a fixed concentration of the IS $\left(5.00 \mathrm{ng} \mathrm{mL}{ }^{1}\right)$ were prepared in the pooled and the extracted pooled human plasma matrices.

\section{Linear calibration curve}

MLN0128 calibration curve was constructed using nine non-zero plasma calibrators, one single-blank (with the IS only), and one double-blank plasma (without MLN0128 or the IS). The concentrations of non-zero calibrators were $0.100,0.200,0.500,1.00,2.50,5.00$, 10.0, 25.0 and $50.0 \mathrm{ng} \mathrm{mL}^{1}$ with the IS concentration of $5.00 \mathrm{ng} \mathrm{mL}{ }^{1}$. The peak area ratios of MLN0128 to the IS (y) were plotted vs the concentrations of MLN0128 plasma calibrators $(x)$ with $1 / x$ weighting.

\section{Accuracy, precision and dilution study}

In this work, the intra-assay accuracy and precision were determined using five replicate injections of QC samples at three different concentrations $\left(0.250,3.00\right.$ and $\left.40.0 \mathrm{ng} \mathrm{mL}^{1}\right)$. The inter-assay accuracy and precision were determined using five parallel injections from five identical QCs at three different concentrations (0.250, 3.00 and $40.0 \mathrm{ng} \mathrm{mL}^{1}$ ) in three separate days. Dilution study was conducted using QC concentration at $250 \mathrm{ng} \mathrm{mL}{ }^{1}$, which was 5 times beyond the upper limit of the linear calibration curve $\left(50 \mathrm{ng} \mathrm{mL}{ }^{1}\right)$, and the analysis was carried out after 10 -fold dilution of plasma dilution QC by the pooled blank human plasma.

\section{Stability studies}

The stabilities of the MLN0128 stock solution (1.00 mg mL ${ }^{1}$ ) and plasma QCs (0.250 and $40.0 \mathrm{ng} \mathrm{mL}{ }^{1}$ ) were investigated against test controls at the same concentrations prepared freshly on the day of the experiment. The stability of MLN0128 was determined from five replicates by comparing the mean-peak-area ratio of MLN0128 to the IS in a test sample with that of the test control, and multiplying by $100 \%$.

In the stability studies, the stock solution was kept on bench-top $\left(23^{\circ} \mathrm{C}\right)$ for 6 and $24 \mathrm{~h}$ before dilution to 1.00 and $50.0 \mathrm{ng} \mathrm{mL}{ }^{1}$. The QCs were kept on the bench-top $\left(23^{\circ} \mathrm{C}\right)$ before sample preparation or in an autosampler $\left(4^{\circ} \mathrm{C}\right)$ after sample preparation for 6 and $24 \mathrm{~h}$. For the freeze-thaw study, the QCs were subjected to three freezethaw cycles where the samples were frozen at $-20^{\circ} \mathrm{C}$ for at least $24 \mathrm{~h}$ and thawed at room temperature $\left(23^{\circ} \mathrm{C}\right)$ unassisted. For longterm storage study, the QCs were stored at $-20^{\circ} \mathrm{C}$ and tested up to 2 months. For the above studies, the working solution of the IS (50.0 $\mathrm{ng} \mathrm{mL}{ }^{1}$ ) was prepared freshly on the day of experiment, and added to each sample prior to sample extraction.

\section{RESULTS AND DISCUSSION}

\section{Method development}

\section{Internal standard (IS)}

Owing to the lack of a heavy stable isotope of MLN0128, several commercially available structural analogs such as PP2 (Sigma Aldrich, MO, USA), STK040263 and STK560245 (Vitas-M 
Laboratory, Apeldoorn, Netherlands) were acquired and evaluated as an IS for quantitation of MLN0128. STK040263 was chosen for the subsequent work because it was rapidly and efficiently separated from MLN0128 by isocratic elution, whereas the other structural analogs needed gradient elution to achieve the similar result.

\section{Chemical properties of the analyte and the IS}

Both MLN0128 and STK040263 are small, weak basic, organic molecules with monoisotopic masses of 309 and $225 \mathrm{~g} / \mathrm{mol}$ (Figure 1). The $\log P$ and $\mathrm{pK}_{\mathrm{a}}$ (of conjugate acid) of these compounds calculated by the $A C D /$ Labs ${ }^{\circledR}$ software version 11.02 (Advanced Chemistry Development, Inc., Toronto, Ontario, Canada) are 2.35 and 3.77 for MLN0128, and 1.36 and 4.20 for STK040263, respectively. The $\log P$ values reveal the hydrophobic nature of these compounds, whereas the $\mathrm{pK}_{\mathrm{a}}$ values of the conjugate acids suggest that the amino groups of these compounds are protonated at low $\mathrm{pH}$ values. These chemical properties of the analyte and the IS guided us in the selections of solvent, mobile phase and chromatographic column.

\section{Mass spectrometric detection}

In this work, a triple quadrupole tandem mass spectrometer (MS/MS) was used for analyte detection owing to its high selectivity and low limit of detection. Since MLN0128 and the IS were readily protonated in the acidic mobile phase $(\mathrm{pH} 2.8)$, positive electrospray ionization $\left(\mathrm{ESI}^{+}\right)$ was chosen as a means of sample introduction. As shown in Figure 1, MLN0128 and the IS readily produced protonated molecules $[\mathrm{MLN} 0128+\mathrm{H}]^{+}$at $\mathrm{m} / \mathrm{z} 310$ (Figure 1a) and $[\mathrm{IS}+\mathrm{H}]^{+}$at $\mathrm{m} / \mathrm{z} 226$ (Figure $1 \mathrm{~b}$ ) in the ionization chamber of the mass spectrometer, and these precursor ions were further fragmented in the collision cell into predominant product ions at m/z 268 for MLN0128 and at m/z 127 for the IS. These predominant product ions were further confirmed using an Agilent 6540 UHD Accurate-Mass Q-TOF LC/MS system (Agilent Technologies, Santa Clara, CA, USA) (data not shown), and the chemical structures of these ions were postulated (Figure 1a and $b$ ) with the aid of Agilent Molecular Formula Generator and Molecular Structure Coordinator software. In the case of product ion of the IS ( $m / z$ 127), there was no structure suggested by the software; the postulated structure was hypothesized based on the chemical structure of the precursor ion and the found fragment formula $\left(\mathrm{C}_{10} \mathrm{H}_{7}{ }^{+}\right)$of the product ion. MRM mode was adopted for quantitation of MLN0128 with the mass transitions of $\mathrm{m} / \mathrm{z} 310 \rightarrow 268$ for MLN0128 and $\mathrm{m} / \mathrm{z}$ $226 \rightarrow 127$ for the IS, respectively.

\section{Liquid chromatographic separation}

Owing to the hydrophobic nature of MLN0128 and STK040263, reversed-phase chromatographic columns were considered for analytical separation. Several columns including Waters MS ${ }^{\circledR}$ XTerra $C_{18}$, Waters MS XTerra ${ }^{\circledR} \mathrm{C}_{8}$ and Waters Atlantis ${ }^{\circledR}$ T3 (Waters Corporation, Milford, MA, USA) were tested. Among them, the Waters XTerra ${ }^{\circledR}$ MS $\mathrm{C}_{18}$ column was chosen because it exhibited more symmetrical and sharper peaks with improved resolution and signal-to-noise ratio in comparison to the others.

Because both MLN0128 and STK040263 are amine derivatives, they have tendency to adsorb on the silica solid support. The use of ammonium formate $(10.0 \mathrm{mM}$ at $\mathrm{pH} 2.8)$ as a component of the mobile phase not only promotes the formation of protonated analytes, but also dynamically competes with the analyte and the IS to prevent (a) $[\mathrm{MLN} 0128+\mathrm{H}]^{+}$
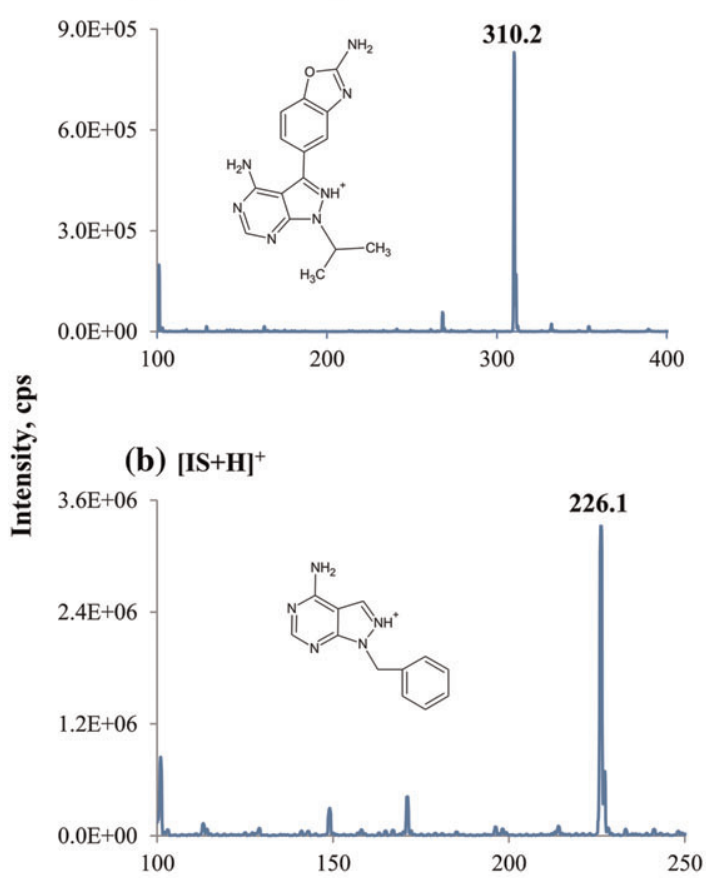

Product ions of m/z 310.2 (MLN0128)

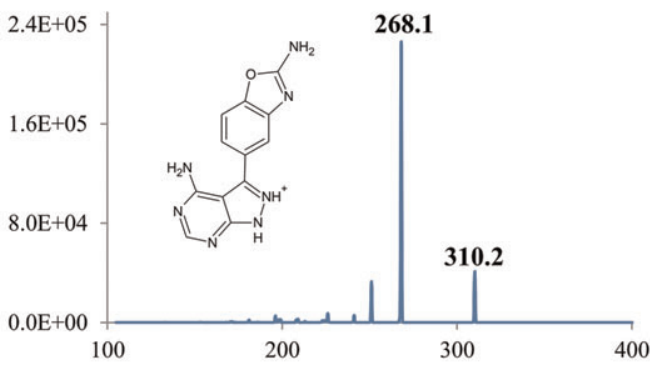

Product ions of $\mathrm{m} / \mathrm{z} 226.1$ (IS)

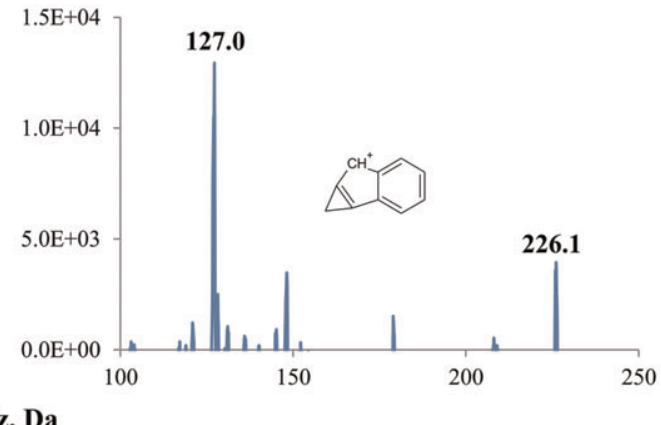

FIGURE 1 The mass spectra of precursor and product ions of MLN0128 and STK040263. Experimental conditions were the same as those described in the section 'Tandem mass spectrometry' 
chemical tailing on the column (Hansen, Helboa, \& Lund, 1984; McDowall, Pearce, \& Murkitt, 1989). Furthermore, for achieving a proper solvent strength and selectivity, a mixture of methanol and acetonitrile at a ratio of 85:15 ( $/ / \mathrm{v})$ was used as another component of the mobile phase for rapid and efficient separation of the analyte and the IS.

For this work, the optimized liquid chromatographic separation was obtained using a Waters $X T$ Terra ${ }^{\circledR} M S \quad C_{18}$ column, and a mobile phase consisting $60 \%$ of ammonium formate $(10.0 \mathrm{mM}$, $\mathrm{pH} 2.8$ ) and $40 \%$ methanol-acetonitrile $(85 / 15, \mathrm{v} / \mathrm{v})$ pumped at a flow rate of $0.300 \mathrm{~mL}$ min ${ }^{1}$. The total run time was $4.00 \mathrm{~min}$ with retention times of 1.95 and 2.94 min for the IS and MLN0128, respectively (Figure 2 ).

\section{Plasma sample preparation}

Both protein precipitation and liquid-liquid extraction (LLE) were investigated as plasma sample preparation methods in this work. Even though protein precipitation was simpler to do, but it gave a lower analyte recovery and stronger matrix effect in comparison to LLE (data not shown).

For the LLE study, several organic solvents such as MTBE, ethyl acetate, isopropanol and hexane were investigated as extraction solvents for plasma sample either alone or in combination. While MTBE showed the highest extraction efficiency, hexane yielded none. Therefore, MTBE was chosen as the organic solvent for the sample preparation by LLE. Figure 3 shows the matrix effect of the MTBE-extracted blank plasma injected by the autosampler on
FIGURE 2 The mass chromatograms of MLN0128 and IS in human plasma. (a) double blank plasma (with neither MLN0128 nor IS);

(b) single blank plasma (with IS only at $50.0 \mathrm{ng} \mathrm{mL}^{1}$ ); and (c) at LLOQ (MLN0128 at $0.100 \mathrm{ng} \mathrm{mL}^{1}$ and IS at $50.0 \mathrm{ng} \mathrm{mL}{ }^{1}$ ). Experimental conditions were the same as those described in the sections 'Liquid chromatography' and 'Tandem mass spectrometry'

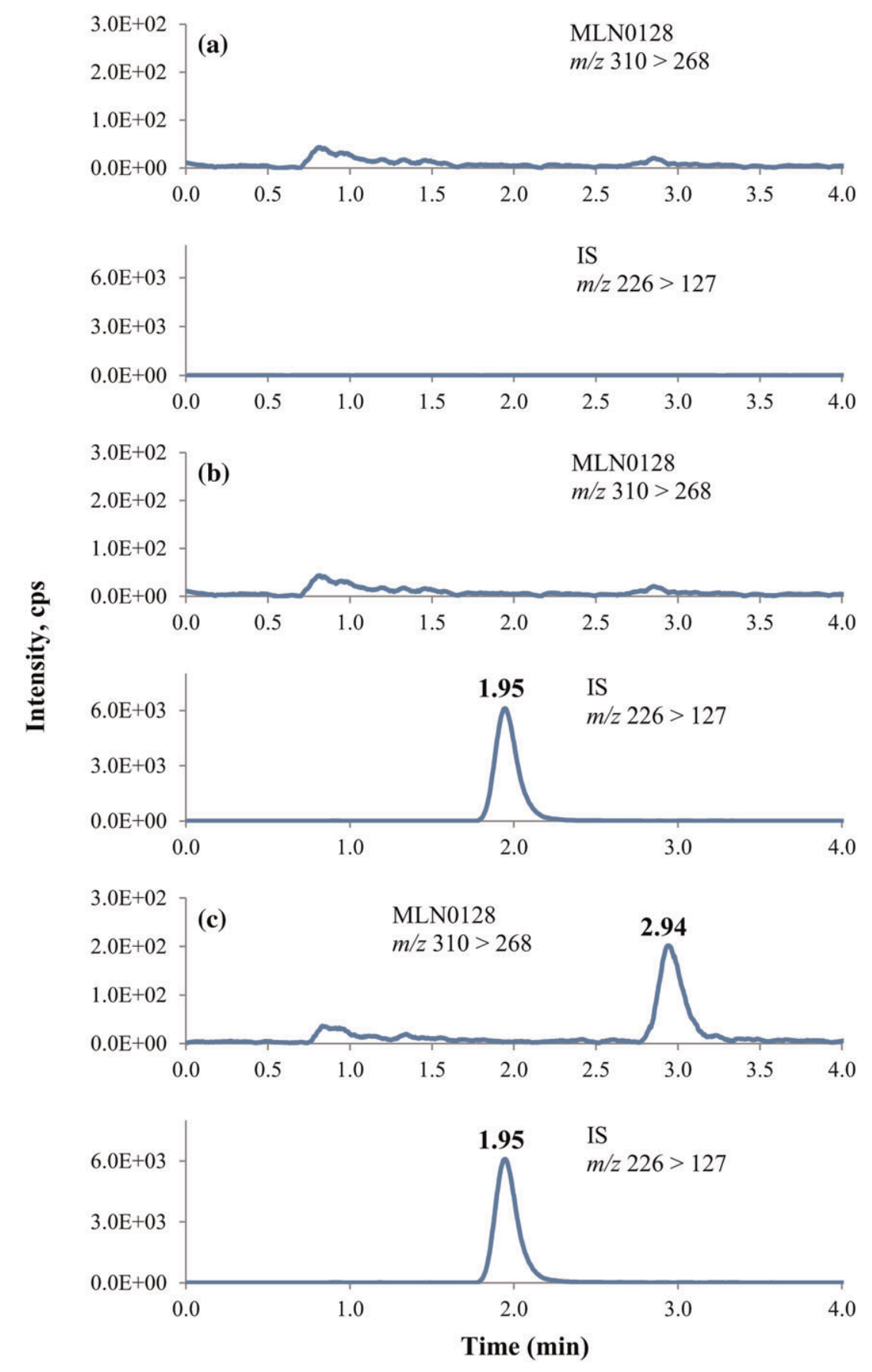



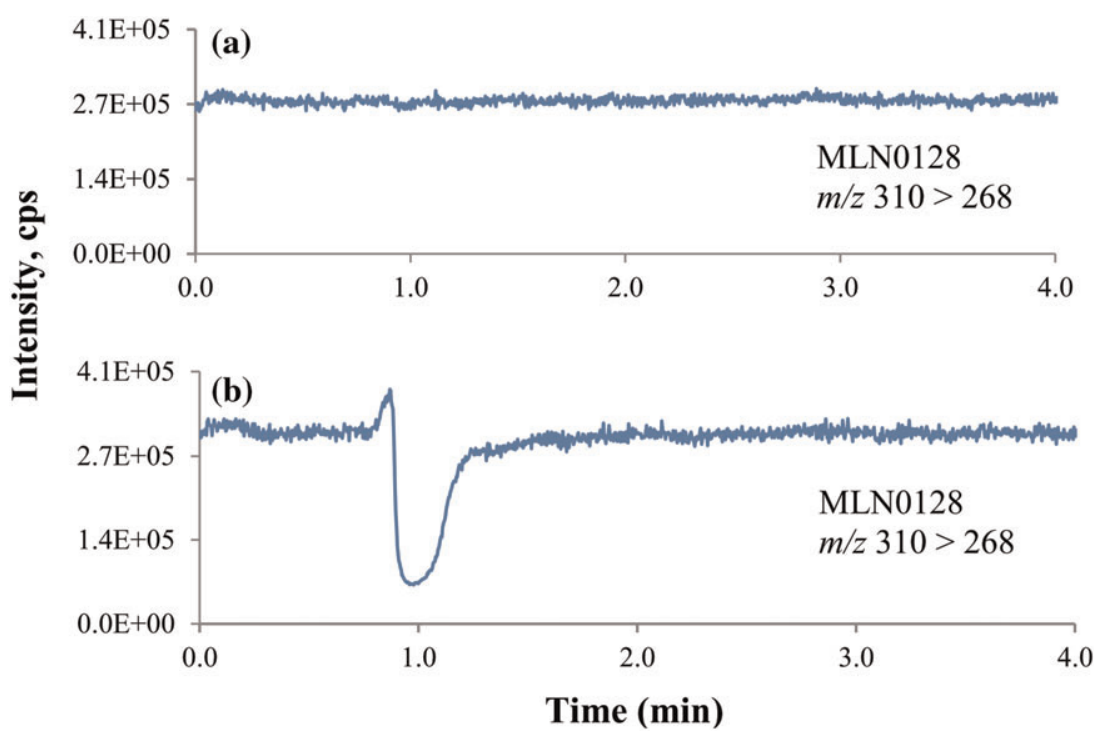

FIGURE 3 The mass chromatograms of postcolumn infusion of MLN0128. (a) injection of $10.0 \mu \mathrm{L}$ mobile phase; and (b) injection of 10.0 $\mu \mathrm{L}$ MTBE extract of blank human plasma. The LC-MS conditions were the same as those in Figure 2, and the post-column infusion of MLN0128 (500 ng mL ${ }^{1}$ ) was carried out by an integrated syringe pump through a three-port mixing tee at a flow rate of $10.0 \mu \mathrm{L} \mathrm{min}^{1}$

the analytical signal of analyte standard solution (i.e. the baseline signal) via post-column infusion, which revealed that the matrix effect (i.e. signal elevation or suppression) mainly occurred in the retention times between 0.80 and $1.50 \mathrm{~min}$, and did not affect the analytical signals of the IS and MLN0128 at the peak values of 1.95 and $2.94 \mathrm{~min}$, respectively.

\section{Reconstitution solution}

During plasma sample preparation, MTBE extract containing the analyte and the IS was dried under nitrogen gas, and the resultant residue was reconstituted in a reconstitution solution for the subsequent LC-MS/MS analysis. For this work, the mobile phase was initially used as the reconstitution solution to reconstitute the dried residue; however, it produced a cloudy solution (colloidal suspension) and caused injection problems. In an attempt to remove the cloudiness of the reconstitute, various ratio of acetonitrile-methanol as the organic components of the mobile phase, and various buffer compositions (e.g. ammonium formate, ammonium acetate or ammonium bicarbonate) and concentrations (e.g. $5.00-20.0 \mathrm{~mm}$ ) as the aqueous component of the mobile phase were tested, and showed no change on the cloudiness of the reconstitute. Eventually, the use of lower percentage of organic solvent in reconstitution solution [i.e. $10 \% \mathrm{MeOH}$ with $90 \%$ ammonium formate solution $(10 \mathrm{mM}, \mathrm{pH} 2.8)]$ resulted in clear sample solution. Therefore, $10 \% \mathrm{MeOH}$ with $90 \%$ ammonium formate solution (10 mM, $\mathrm{pH} 2.8)$ was chosen as the reconstitution solution of the subsequent work.

\section{Method validation}

\section{Selectivity and LLOQ}

The selectivity and the LLOQ of the method were examined in this work. As illustrated by the representative mass chromatograms of the double blank plasma (Figure 2a) recorded at the same mass transitions of MLN0128 and the IS, while no detectable interference was observed at the same retention time of IS, a tiny endogenous interferent peak was detected near the retention time of MLN0128. The representative mass chromatograms of the single blank plasma (Figure 2b) showed that the interferent was not a part of the IS. Since the mean peak area of the endogenous interferent from six different individual double blank plasmas was $<6 \%$ of that of MLN0128 at the LLOQ (Figure 2c), which was much lower than the limit set by US Food and Drug Administration ( $\leq 20 \%$ ), the interferent was tolerated at the LLOQ in this method. The LLOQ of this method was $0.100 \mathrm{ng} \mathrm{mL}^{1}$ for MLN0128, which had accuracy and precision $\leq \pm 9$ and $\leq 7 \%$ (Table 1), assessed by five replicate measurements of six plasma calibrators at LLOQ each prepared by a different individual blank plasma.

\section{Matrix effect and recovery}

Matrix effect was assessed by the MF of MLN0128 at three QC concentrations in six individual plasma matrices. As shown in Table 2,

TABLE 1 Accuracy and precision of MLN0128 at LLOQ in six individual lots of human plasma $(n=5)$

\begin{tabular}{|c|c|c|c|c|c|}
\hline Plasma matrix & Nominal [MLN0128] (ng mL ${ }^{-1}$ ) & Mean measured [MLN0128] (ng mL $\mathrm{mL}^{-1}$ ) & $\mathrm{SD}\left(\mathrm{ng} \mathrm{mL} \mathrm{L}^{-1}\right.$ ) & Precision $(\mathrm{CV}, \%)^{\mathrm{a}}$ & Accuracy (RE, \%) \\
\hline Lot 1 & 0.100 & 0.104 & 0.001 & 1 & 4 \\
\hline Lot 2 & 0.100 & 0.101 & 0.004 & 4 & 1 \\
\hline Lot 3 & 0.100 & 0.093 & 0.003 & 3 & -7 \\
\hline Lot 4 & 0.100 & 0.102 & 0.007 & 7 & 2 \\
\hline Lot 5 & 0.100 & 0.096 & 0.003 & 3 & -4 \\
\hline Lot 6 & 0.100 & 0.109 & 0.003 & 3 & 9 \\
\hline
\end{tabular}

${ }^{\mathrm{a} C V}$ (Standard deviation/mean) $\times 100 \%$.

${ }^{\mathrm{b}} \mathrm{RE}[($ measured nominal)/(nominal) $] \times 100 \%$. 
TABLE 2 Matrix factors of MLN0128 QCs in six individual lots of human plasma $(n=5)$

\begin{tabular}{|c|c|c|c|c|}
\hline $\begin{array}{l}\text { Plasma } \\
\text { matrix }\end{array}$ & $\begin{array}{c}\text { [MLN0128] } \\
\left(\mathrm{ng} \mathrm{mL}^{-1}\right)\end{array}$ & $\begin{array}{l}\text { MF }_{\text {MLNO128 }} \\
\quad \pm \mathrm{SD}^{\mathrm{a}}\end{array}$ & $\mathrm{MF}_{\mathrm{IS}} \pm S \mathrm{~S}^{\mathrm{b}}$ & $\begin{array}{l}\text { IS normalized } \\
\text { MF } \pm \text { SD }^{c}\end{array}$ \\
\hline \multirow[t]{3}{*}{ Lot 1} & 0.250 & $1.02 \pm 0.02$ & $0.94 \pm 0.02$ & $1.08 \pm 0.04$ \\
\hline & 3.00 & $1.02 \pm 0.03$ & $0.95 \pm 0.01$ & $1.07 \pm 0.02$ \\
\hline & 40.0 & $0.99 \pm 0.02$ & $0.96 \pm 0.01$ & $1.04 \pm 0.02$ \\
\hline \multirow[t]{3}{*}{ Lot 2} & 0.250 & $0.96 \pm 0.03$ & $0.91 \pm 0.02$ & $1.05 \pm 0.05$ \\
\hline & 3.00 & $1.00 \pm 0.02$ & $0.98 \pm 0.01$ & $1.02 \pm 0.03$ \\
\hline & 40.0 & $0.98 \pm 0.01$ & $0.98 \pm 0.01$ & $1.00 \pm 0.02$ \\
\hline \multirow[t]{3}{*}{ Lot 3} & 0.250 & $0.98 \pm 0.06$ & $1.00 \pm 0.01$ & $0.98 \pm 0.05$ \\
\hline & 3.00 & $0.99 \pm 0.01$ & $0.98 \pm 0.01$ & $1.01 \pm 0.02$ \\
\hline & 40.0 & $0.93 \pm 0.01$ & $0.97 \pm 0.01$ & $0.96 \pm 0.01$ \\
\hline \multirow[t]{3}{*}{ Lot 4} & 0.250 & $1.04 \pm 0.06$ & $1.02 \pm 0.01$ & $1.01 \pm 0.06$ \\
\hline & 3.00 & $1.01 \pm 0.01$ & $1.00 \pm 0.01$ & $1.01 \pm 0.01$ \\
\hline & 40.0 & $0.96 \pm 0.01$ & $0.95 \pm 0.02$ & $1.01 \pm 0.01$ \\
\hline \multirow[t]{3}{*}{ Lot 5} & 0.250 & $0.99 \pm 0.04$ & $0.99 \pm 0.00$ & $1.00 \pm 0.04$ \\
\hline & 3.00 & $0.99 \pm 0.01$ & $0.97 \pm 0.02$ & $1.02 \pm 0.01$ \\
\hline & 40.0 & $0.97 \pm 0.01$ & $0.95 \pm 0.01$ & $1.02 \pm 0.02$ \\
\hline \multirow[t]{3}{*}{ Lot 6} & 0.250 & $1.0 \pm 0.1$ & $1.03 \pm 0.01$ & $1.0 \pm 0.1$ \\
\hline & 3.00 & $0.98 \pm 0.02$ & $0.96 \pm 0.03$ & $1.02 \pm 0.02$ \\
\hline & 40.0 & $0.94 \pm 0.02$ & $0.92 \pm 0.03$ & $1.02 \pm 0.02$ \\
\hline
\end{tabular}

${ }^{a} \mathrm{MF}_{\mathrm{MLN0128}}$ (mean peak area of MLN0128 in the extracted plasma matrix)/(mean peak area of MLN0128 in the reconstitution solution).

${ }^{\mathrm{b}} \mathrm{MF}_{\mathrm{IS}}$ (mean peak area of the IS in the extracted plasma matrix)/(mean peak area of the IS in the reconstitution solution).

${ }^{\mathrm{C}}$ IS normalized MF $\mathrm{MF}_{\mathrm{MLNO} 128} / \mathrm{MF}_{\mathrm{IS}}$.

the absolute MFs of MLN0128 and the IS were 0.93-1.04 and 0.91-1.03, respectively, and the IS normalized MFs were 0.96-1.08. These data revealed that the matrix effect of human plasma was negligible in the measurements of MLN0128 and the IS when MTBE was used as organic solvent for the analyte extraction.

The recoveries of MLN0128 at three different QC concentrations in pooled human plasma are summarized in Table 3. The absolute recoveries of MLN0128 and the IS were 79-84 and 81-84\%, respectively, and the IS normalized recoveries were 95-100\%. These results indicated that MTBE extraction used was efficient and consistent for the recovery of MLN0128 and the IS from human plasma samples.

\section{Calibration curve}

The mean linear regression equation based on three individual calibration curves in three days was $y=0.516( \pm 0.005) x+0.015( \pm 0.004)$ over the range of $0.100-50.0 \mathrm{ng} \mathrm{mL}^{1}$ with a correlation coefficient of 0.999. As shown in Table 4, the accuracy and precision of individual plasma calibrators were $\leq \pm 6 \%$ and $\leq 7 \%$, respectively.

\section{Assay accuracy, precision and dilution integrity}

As shown in Table 5, the intra-assay accuracy and precision were $\leq \pm 4$ and $\leq 8 \%$, and the inter-assay accuracy and precision were $\leq \pm 4$ and $\leq 2 \%$, respectively, indicating that the method developed was accurate and precise. The dilution studies showed that the intra-assay accuracy and precision were $\leq \pm 3$ and $\leq 3 \%$, and the inter-assay accuracy and precision were $\leq \pm 1$ and $\leq 1 \%$, indicating the integrity of plasma samples could be preserved in sample dilution.

\section{Stability studies of MLN0128}

The stability studies for MLN0128 were conducted and the data are summarized in Table 6. The stock solutions and plasma QCs were found to be stable by free standing on bench-top at room temperature

TABLE 3 Recovery of MLN0128 in pooled human plasma $(n=5)$

\begin{tabular}{|c|c|c|c|}
\hline [MLN0128] (ng mL mL $^{-1}$ & Recovery $_{M L N 0128}{ }^{a} \pm$ SD (\%) & Recovery $_{\text {IS }}{ }^{b} \pm$ SD (\%) & IS Normalized recovery ${ }^{c} \pm$ SD (\%) \\
\hline 0.250 & $84 \pm 3$ & $84 \pm 1$ & $100 \pm 3$ \\
\hline 3.00 & $80 \pm 2$ & $84 \pm 3$ & $95 \pm 3$ \\
\hline 40.0 & $79 \pm 1$ & $81 \pm 2$ & $98 \pm 1$ \\
\hline
\end{tabular}

${ }^{\text {a Recovery }}$ MLN0128 $[($ mean peak area of MLN0128 in plasma matrix)/(mean peak area of MLN0128 in extracted plasma matrix) $] \times 100 \%$.

${ }^{\mathrm{b}}$ Recovery IS [(mean peak area of IS in plasma matrix)/(mean peak area of IS in extracted plasma matrix)] × 100\%.

'IS normalized recovery $\left[\left(\right.\right.$ Recovery $\left._{\mathrm{MLNO} 128}\right) /\left(\right.$ Recovery $\left.\left._{\text {IS }}\right)\right] \times 100 \%$.

PA mean peak area.

TABLE 4 Accuracy and precision of plasma MLN0128 calibrators in three validation batches over three different days

\begin{tabular}{|c|c|c|c|c|}
\hline Nominal [MLN0128] $\left(\mathrm{ng} \mathrm{mL}^{-1}\right)$ & Measured [MLN0128] $\left(\mathrm{ng} \mathrm{mL}^{-1}\right)$ & $\mathrm{SD}\left(\mathrm{ng} \mathrm{mL}^{-1}\right.$ ) & Precision (CV, \%) & Accuracy (RE, \%) \\
\hline 0.100 & 0.101 & 0.008 & 7 & 0.6 \\
\hline 0.200 & 0.203 & 0.006 & 3 & 1 \\
\hline 1.00 & 0.978 & 0.006 & 0.6 & -2 \\
\hline 2.50 & 2.5 & 0.1 & 3 & 1 \\
\hline 25.0 & 26.4 & 0.5 & 2 & 6 \\
\hline 50.0 & 48.8 & 0.7 & 1 & -2 \\
\hline
\end{tabular}


TABLE 5 Intra- and inter-assay accuracy and precision of MLN0128 in pooled human plasma $(n=5)$

\begin{tabular}{|c|c|c|c|c|}
\hline Nominal [MLN0128] $\left(\mathrm{ng} \mathrm{mL}^{-1}\right)$ & Measured [MLN0128] (ng mL ${ }^{-1}$ ) & $\mathrm{SD}\left(\mathrm{ng} \mathrm{mL} \mathrm{L}^{-1}\right.$ ) & $\mathrm{CV}, \%$ & RE, \% \\
\hline \multicolumn{5}{|l|}{ Intra-assay ${ }^{a}$} \\
\hline 0.250 & 0.249 & 0.007 & 3 & -0.6 \\
\hline 40.0 & 38 & 3 & 8 & -4 \\
\hline $250^{c}$ & 257 & 7 & 3 & 3 \\
\hline 3.00 & 2.88 & 0.05 & 2 & -4 \\
\hline 40.0 & 38.3 & 0.6 & 1 & -4 \\
\hline $250^{c}$ & 253 & 4 & 1 & 1 \\
\hline
\end{tabular}

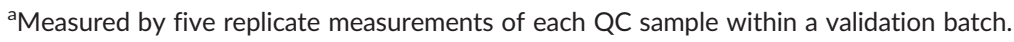

${ }^{b}$ Measured by five parallel measurements of five identical QC samples at each concentration over three validation batches.

${ }^{\mathrm{c}}$ Dilution QC was measured after a 10-fold dilution with pooled blank human plasma and the reported concentration was back calculated by multiplying a factor of 10.

TABLE 6 Stabilities of MLN0128 under various test conditions $(n=5)$

\begin{tabular}{|c|c|c|c|c|}
\hline \multirow[b]{2}{*}{ Test conditions } & \multirow[b]{2}{*}{ Temperature $\left({ }^{\circ} \mathrm{C}\right)$} & \multirow[b]{2}{*}{ MLN0128 } & \multicolumn{2}{|c|}{ Recovery \pm SD (\%) } \\
\hline & & & $6 \mathrm{~h}$ & $24 \mathrm{~h}$ \\
\hline Bench-top & 23 & Stock solution ${ }^{a}$ & $100 \pm 1$ & $101 \pm 1$ \\
\hline \multirow[t]{2}{*}{ Bench-top } & 23 & Low $\mathrm{QC}^{\mathrm{c}}$ & $98 \pm 4$ & $105 \pm 5$ \\
\hline & & High $\mathrm{QC}^{\mathrm{c}}$ & $94 \pm 1$ & $97 \pm 2$ \\
\hline \multirow[t]{2}{*}{ Three freeze thaw cycles } & -2023 & Low QC & $102 \pm 2$ & $94 \pm 1$ \\
\hline & & High QC & $99 \pm 1$ & $92 \pm 1$ \\
\hline \multirow[t]{2}{*}{ Long term (60 days) } & -20 & Low QC & & $101 \pm 1$ \\
\hline & & High QC & & $95 \pm 1$ \\
\hline
\end{tabular}

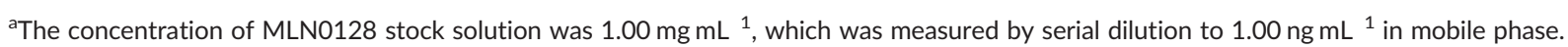

${ }^{\text {b}}$ The concentration of MLN0128 stock solution was $1.00 \mathrm{mg} \mathrm{mL}{ }^{1}$, which was measured by serial dilution to $50.0 \mathrm{ng} \mathrm{mL}{ }^{1}$ in mobile phase.

${ }^{\mathrm{c}}$ The concentration of plasma low and high QCs were 0.250 and $40.0 \mathrm{ng} \mathrm{mL}{ }^{1}$, respectively.

for at least $24 \mathrm{~h}$ prior to sample preparation with recoveries of 99-101 and $94-105 \%$, respectively. The plasma QCs were also stable for at least $24 \mathrm{~h}$ in autosampler set at $4^{\circ} \mathrm{C}$ post sample preparation with recoveries of $91-104 \%$. The recoveries of plasma QCs after three freeze-thaw cycles were 92-102\%, and after long-term (2 months) storage at $-20^{\circ} \mathrm{C}$ recoveries were $95-101 \%$. These studies showed that there were no significant losses of MLN0128 under the test conditions.

\section{Method application}

The method developed was intend to support the proposed clinical studies of MLN0128 in a 'Randomized Pilot Phase 0 and FLT-PET/MRI Imaging Biomarker Study of MLN0128 in Recurrent Glioblastoma Multiforme' and a 'Phase 1 Study of MLN0128 with Bevacizumab' from the Case Comprehensive Cancer Center in response to the $\mathrm{NCl} / \mathrm{CTEP}$ solicitation in 2013. Even though both proposals were not funded eventually, the validated method may be used by the scientific community for preclinical and clinical studies of MLN0128.

\section{CONCLUSIONS}

A rapid and selective LC-MS/MS method has been developed for the quantitative determination of MLN0128 in human plasma. In this method, MLN0128 and the IS were extracted from human plasma by an LLE procedure, and separated by reversed-phase chromatography with isocratic elution. Quantitation of MLN0128 was carried out by internal calibration and positive electrospray ionization tandem mass spectrometry operated in MRM mode. This method has been validated according to US Food and Drug Administration guidance for industry on bioanalytical method validation. It may be used in clinical studies of MLN0128 in human. 


\section{ACKNOWLEDGMENT}

This research was supported by the Translational Research Core

Facility of the Case Comprehensive Cancer Center (P30 CA43703).

\section{REFERENCES}

Burris, H., Hart, L., Kurkjian, C., Berk, G., Lipman, P., Patel, C., ... Infante, J. (2012). $605 \mathrm{~A}$ phase 1, open label, dose-escalation study of oral administration of the investigational agent MLN0128 in combination with paclitaxel $(\mathrm{P})$ in patients $(\mathrm{pts})$ with advanced solid malignancies. European Journal of Cancer, 48, 605.

Edlind, M., \& Hsieh, A. (2014). PI3K-AKT mTOR signaling in prostate cancer progression and androgen deprivation therapy resistance. Asian Journal of Andrology, 16, 378386.

Fabrey, R., Atienza, J., Briere, D., Brake, R., \& Vincent, P. W. (2013). Abstract C264: effective preclinical treatment of KRAS mutant lung cancers with a combination of MLN0128, an investigational novel mTORC1/2 inhibitor, and a selective MEK inhibitor. Molecular Cancer Therapeutics, 12, C264.

Gökman-Polar, Y., Liu, Y., Toroni, R. A., Sanders, K. L., Mehta, R., Badve, S., ... Sledge, G. W. Jr. (2012). Investigational drug MLN0128, a novel TORC1/2 inhibitor, demonstrates potent oral antitumor activity in human breast cancer xenograft models. Breast Cancer Research and Treatment, 136, 673682

Guertin, D. A., \& Sabatini, D. M. (2007). Defining the Role of mTOR in Cancer. Cancer Cell, 12, 922.

Hansen, S. H., Helboa, P., \& Lund, U. (1984). Absorption and partition chromatography. In Z. Deyl (Ed.), Separation Method (pp. 184). New York: Elsevier.

Infante, J. R., Tabernero, J., Cervantes, A., Jalal, S., Burris, H. A., Macarulla, T., ... Gordon, M. (2013). Abstract C252: A phase 1, dose-escalation study of MLN0128, an investigational oral mammalian target of rapamycin complex 1/2 (mTORC1/2) catalytic inhibitor, in patients (pts) with advanced nonhematologic malignancies. Molecular Cancer Therapeutics, 12, C252.

Ingels, A., Zhao, H., Thong, A. E., Saar, M., Valta, M. P., Nolley, R., ... Peehl, D. M. (2014). Preclinical trial of a new dual mTOR inhibitor, MLN0128, using renal cell carcinoma tumorgrafts. International Journal of Cancer, 134, 23222329.
Inoki, K., Zhu, T. F., \& Guan, K. L. (2003). TSC2 mediates cellular energy response to control cell growth and survival. Cell, 115, 577590.

Janes, M. R., Vu, C., Mallya, S., Shieh, M., Limon, J. J., Li, L.-S., ... Fruman, D. A. (2013). Efficacy of the investigational mTOR kinase inhibitor MLN0128/ INK128 in models of B-cell acute lymphoblastic leukemia. Leukemia, 27, 586594.

Liu, Y., Jessen, K., Wang, S., Kessler, L., Li, L., Darjania, L., ... Rommel, C. (2010). 482 INK128, a potent and selective TORC1/2 inhibitor, demonstrates anti-tumor activity in preclinical models of renal cell carcinoma by a distinct mechanism. EJC Supplements, 8, 154155.

McDowall, R. D., Pearce, J. C., \& Murkitt, G. S. (1989). Sample preparation using bonded silica: Recent experiences and new instrumentation. Trends in Analytical Chemistry, 8, 134140.

Meric-Bernstam, F., \& Gonzalez-Angulo, A. M. (2009). Targeting the mTOR signaling network for cancer therapy. Journal of Clinical Oncology, 27, 22782287.

Neshat, M. S., Mellinghoff, I. K., Tran, C., Stiles, B., Thomas, G., Petersen, R., ... Sawyers, C. L. (2001). Enhanced sensitivity of PTENdeficient tumors to inhibition of FRAP/mTOR. Proceedings of the National Academy of Sciences of the United States of America, 98, 1031410319.

Schenone, S., Brullo, C., Musumeci, F., Radi, M., \& Botta, M. (2011). ATP-competitive inhibitors of mTOR: an update. Current Medicinal Chemistry, 18, 29953014.

Shaw, R. J., Bardeesy, N., Manning, B. D., Lopez, L., Kosmatka, M., DePinho, R. A., \& Cantley, L. C. (2004). The LKB1 tumor suppressor negatively regulates mTOR signaling. Cancer Cell, 6, 9199.

US Food and Drug Administration. Guidance for Industry: Bioanalytical Method Validation, 2001. Available from: http://www.fda.gov/ downloads/Drugs/GuidanceComplianceRegulatorylnformation/Guidances/ UCM070107.pdf Accessed August 7, 2016.

Vivanco, I., \& Sawyers, C. L. (2002). The phosphatidylinositol 3-kinase AKT pathway in human cancer. Nature Reviews Cancer, 2, 489501.

How to cite this article: Kunati SR, Xu Y. Determination of MLN0128, an investigational antineoplastic agent, in human plasma by LC-MS/MS. Biomed. Chromatogr. 2017;31:e3818. https://doi.org/10.1002/bmc.3818 